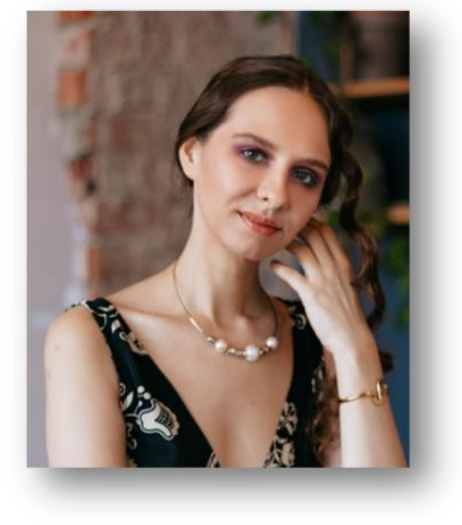

\section{СОВЕРШЕНСТВОВАНИЕ СИСТЕМЫ ПОЖАРНОЙ АВТОМАТИКИ ЗДАНИЯ С МАССОВЫМ ПРЕБЫВАНИЕМ ЛЮДЕЙ}

Т.С. Станкевич, магистрант, e-mail: TSeStankevich@stud.kantiana.ru ФГАОУ ВО «Балтийский Федеральный университет им. И. Канта»

Рассмотрены практические особенности проектирования и функционирования системы пожарной автоматики объекта с массовым пребыванием людей (объект торговли). Сформулированы предложения по совершенствованию системы пожарной автоматики объекта, заключающиеся в замене существующей системы на адресно-аналоговую систему пожарной сигнализации и в разработке и внедрении системы автоматического водяного пожаротушения.

Ключевые слова: пожар, пожарная автоматика, сигнализаџия, оповещение, пожаротушение

\title{
ВВЕДЕНИЕ
}

В соответствии со статистическими данными, представленными в [1], на объектах торговли в РФ ежегодно регистрируется значительное количество пожаров: в 2020 г. 838 пожаров; в 2019 г. - 905; в 2018 г. - 865; в 2017 г. - 982 пожара. Распределение по объектам представлено в табл. 1. Статистические данные для Калининградской области представлены в табл. 2.

Таблица 1 - Распределение пожаров на объектах торговли в РФ

\begin{tabular}{|l|c|c|c|c|}
\hline Объект & 2017 г. & 2018 г. & 2019 г. & 2020 г. \\
\hline Крытый рынок розничной и (или) оптовой торговли & 50 & 38 & 36 & 40 \\
\hline $\begin{array}{l}\text { Открытый рынок розничной и (или) оптовой } \\
\text { торговли }\end{array}$ & 13 & 10 & 9 & 20 \\
\hline Торговый павильон & 424 & 353 & 407 & 376 \\
\hline Киоск, ларек, палатка, в т.ч. контейнерного типа & 495 & 464 & 453 & 402 \\
\hline
\end{tabular}

Таблица 2 - Распределение пожаров на объектах торговли в Калининградской области

\begin{tabular}{|l|c|c|c|c|}
\hline Объект & 2017 г. & 2018 г. & 2019 г. & 2020 г. \\
\hline Крытый рынок розничной и (или) оптовой торговли & 0 & 0 & 1 & 0 \\
\hline $\begin{array}{l}\text { Открытый рынок розничной и (или) оптовой } \\
\text { торговли }\end{array}$ & 1 & 0 & 0 & 0 \\
\hline Торговый павильон & 0 & 1 & 4 & 1 \\
\hline Киоск, ларек, палатка, в т.ч. контейнерного типа & 7 & 3 & 1 & 2 \\
\hline
\end{tabular}

К первоочередным задачам обеспечения пожарной безопасности объектов торговли являются установка систем пожарной автоматики. 


\section{ОБЪЕКТ ИССЛЕДОВАНИЯ}

Объект исследования - объект торговли с массовым пребыванием людей.

\section{ЦЕЛЬ И ЗАДАЧИ ИССЛЕДОВАНИЯ}

Цель - совершенствование системы пожарной автоматики объекта торговли с массовым пребыванием людей.

Задачи исследования: изучение особенностей построения и функционирования системы обеспечения пожарной автоматики объекта; формулирование мероприятий, направленных на совершенствование системы пожарной автоматики объекта.

\section{МЕТОДЫ ИССЛЕДОВАНИЯ}

Использованы методы системного анализа и методы проектирования систем.

\section{РЕЗУЛЬТАТЫ ИССЛЕДОВАНИЯ}

В работе использованы данные анализа системы пожарной безопасности рынка из [2]. Согласно [2], указанный объект является зданием для временного пребывания людей, по СП 255.1325800 .2016 [3] рынок относится к категории «открытые и крытые спортивнофизкультурные, зрелищные и торговые сооружения».

В [3] указано, что типом основного перекрытия является железобетонное, полы бетонные, энергоснабжение городское, освещение электрическое, канализация используется центральная городская. Отопление объекта осуществляется от собственной автономной газовой котельной. Предусмотрена естественная и принудительная вентиляция. Здание имеет девять эвакуационных выходов: три выхода в южной части объекта; три выхода в восточной части объекта; три выхода в западной части объекта.

В здании рынка располагается 283 торговых объектов: десять объектов овощного отдела; 24 объекта молочного отдела; 14 объектов колбасного отдела; 11 объектов мясного отдела; 14 объектов бакалейного отдела; 11 объектов рыбного отдела; 20 объектов фермерского отдела; 121 киоск; 16 магазинов; 42 модуля.

Как указано в [2], на объекте имеется система пожарной автоматики, включающая систему автоматического обнаружения пожара, оповещения о нем людей и управления их эвакуацией. В 2021 г. контрольными органами проводилась проверка системы, в ходе которой ее работоспособность подтверждена.

Система пожарной сигнализации объекта включает:

- четыре приемно-контрольных прибора Сигнал-20М;

- один приемно-контрольный прибор Сигнал-20П;

- один пульт контроля и управления С2000М;

- один блок индикации с клавиатурой С2000-БКИ (рис.);

- блоки питания;

- двадцать четыре извещателя пламени Спектрон 201;

- сто восемь извещателей дымовых ИП-212-45;

- етыреста семь извещателей дымовых ИП-212-141;

- четыре извещателя тепловых ИП 101-1А;

- сто тридцать девять извещателей пожарных ручных ИПР 513-10.

В качестве извещателей применяются:

- извещатели пожарные дымовые оптико-электронные ИП 212-45 и ИП 212-141 (питание и передача сигнала «Пожар» осуществляется по двухпроводному шлейфу сигнализации, при срабатывании извещателя происходит включение оптического индикатора);

- тепловые извещатели ИП 101-1А (подача тревожного сигнала произойдет в случае повышения температуры выше порога, заданному датчику, режим работы круглосуточный); 
- извещатели пламени Спектрон 201;

-электронные пожарные ручные извещатели ИПР 513-10 (прибор имеет релейные выходы, с помощью которых можно управлять звуковыми внутренними оповещателями «Иволга», светозвуковыми устройствами «Призма-200» и «Маяк 12К» и др., сигнал о тревоге передается на пульт централизованного наблюдения).

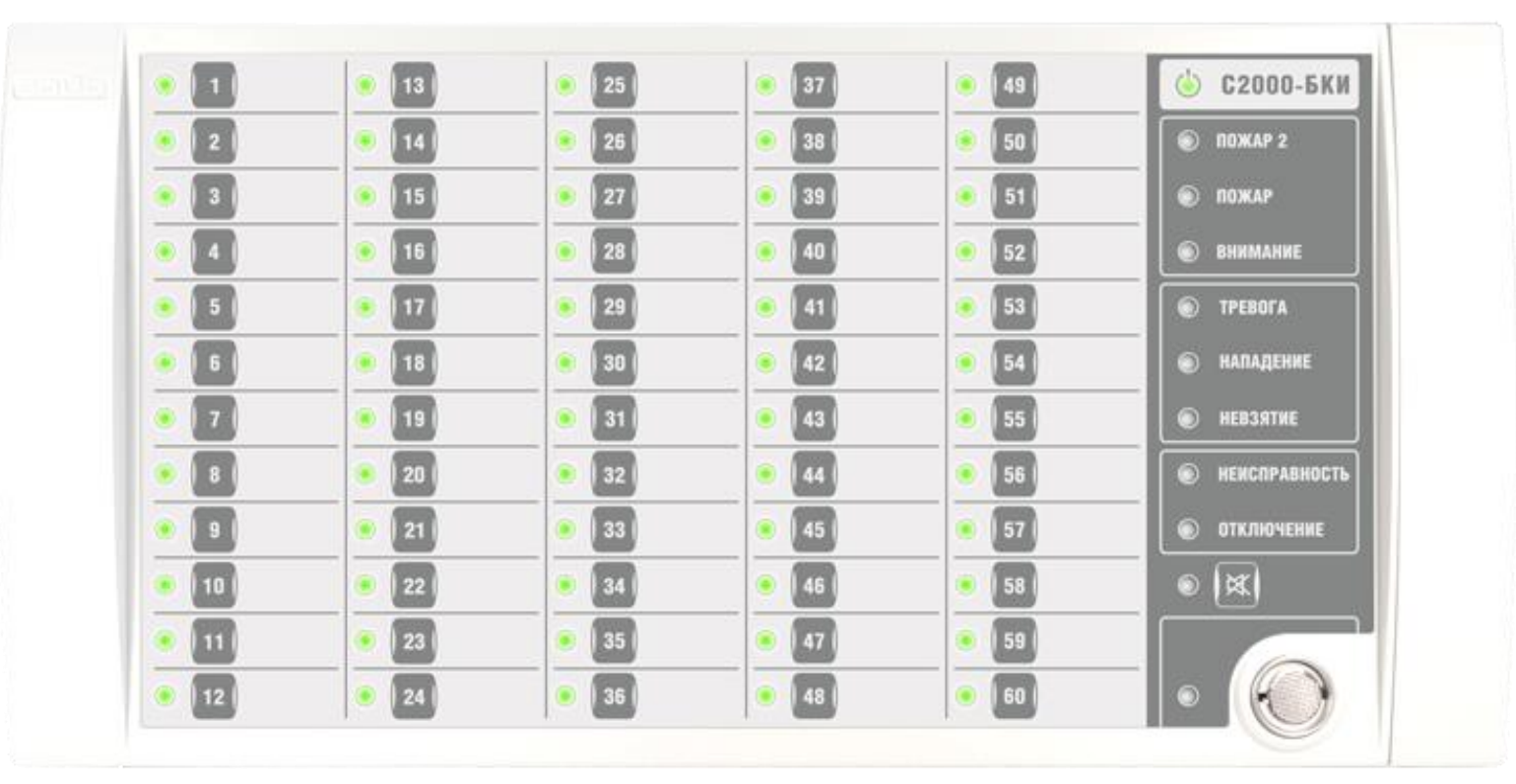

Рисунок - Средство охранно-пожарной сигнализаџиии индикаторный блок с клавиатурой «С2000-БКИ» [4]

Дополнительно в системе установлен блок контроля и индикации «С2000-БКИ» для отображения состояния зон приборов на посту наблюдения. Управление состоянием зон, просмотр событий системы осуществляется с сетевого контроллера - пульта «С2000-М».

Произведен анализ достоинств и недостатков существующей на объекте системы и установлено, что в соответствии с [5] представленные в системе извещатели не обеспечивают достаточного уровня надежности, что требует их дублирования при установке.

Поскольку критерий надежности для объекта с массовым пребыванием людей выходит на первый план в связи с высоким риском гибели и травмирования людей в здании при возникновении пожара, необходимо рассмотреть возможность совершенствования системы пожарной сигнализации путем установки адресно-аналоговой системы. Предполагается использовать нормы и правила проектирования систем пожарной защиты, которые изложены в СП 5.13130.2009 [6].

Кроме того, в ходе исследования объекта выявлено отсутствие системы автоматического пожаротушения на торговом объекте. Предлагается внедрить систему автоматического водяного пожаротушения. При этом оптимальным вариантом является осуществление запуска автоматической установки пожаротушения от адресно-аналоговых извещателей, что позволяет избежать установки дополнительных извещателей.

В рассматриваемом случае с целью сокращения материальных затрат на разработку и внедрение системы предлагается собрать систему пожаротушения с использованием только приемно-контрольных приборов (например, серии «Сигнал») и контрольно-пусковых блоков «С2000-КПБ» под управлением пульта «С2000М» при ручном программировании логики в сетевом контроллере.

Согласно [7], из-за значительного количества направлений тушения оптимальнее использовать схему из одного-двух контроллеров двухпроводной линии связи и контрольнопусковых блоков вместо большого количества приборов «С2000-АСПТ». 


\section{ЗАКЛЮЧЕНИЕ}

Выполнено изучение элементов системы пожарной автоматики объекта с массовым пребыванием людей. Установлено, что существующая система сигнализации объекта торгового назначения со сложной конфигурацией имеет потенциал для улучшения. С учетом специфики объекта защиты и его функций предложено внедрение адресно-аналоговой системы пожарной сигнализации и системы автоматического пожаротушения в систему пожарной автоматики объекта с массовым пребыванием людей.

\section{СПИСОК ЛИТЕРАТУРЫ}

1. Статистика пожаров за 2020 год. Статистический сборник: Пожары и пожарная безопасность в 2020 году; Под общей ред. Д.М. Гордиенко. - Москва: ВНИИПО, 2021. $112 \mathrm{c}$.

2. Семко, Е.Д. Организация спасательных работ на пожаре в здании с массовым пребыванием людей на предприятии ООО «Центральный Торговый Дом плюс»: вып. квал. раб. / Е.Д. Семко. - Калининград, 2021. - 84 с.

3. СП 255.1325800.2016 Свод правил. Здания и сооружения. Правила эксплуатации. Основные положения [Электронный ресурс]. URL: https://docs.cntd.ru/document/1200139958 (дата обращения: 15.10.2021 г).

4. Блок индикации с клавиатурой С200-БКИ. Системы безопасности BOLID [Электронный pecypc]. URL: https://bolid.ru/production/orion/control-units/s2000-bki.html (дата обращения: 15.10.2021).

5. Пожарная сигнализация на базе оборудования «Болид» [Электронный ресурс]. URL: https://pozhproekt.ru/articles/pozharnaya-signalizaciya-na-baze-oborudovaniya-bolid (дата обращения: 07.06.2021).

6. СП 5.13130.2009 Системы противопожарной защиты. Установки пожарной сигнализации и пожаротушения автоматические. Нормы и правила проектирования [Электронный ресурс]. URL: https://www.msu.ru/info/struct/gochs-mgu/docs/sp05.pdf (дата обращения: 15.10.2021).

7. Автоматика установок пожаротушения на базе оборудования «Болид» [Электронный pecypc]. URL: https://pozhproekt.ru/articles/avtomatika-ustanovok-pozharotusheniya-na-bazeoborudovaniya-bolid (дата обращения: 07.06.2021).

\section{IMPROVEMENT OF THE FIRE AUTOMATION SYSTEM OF BUILDINGS (ON THE EXAMPLE OF A MARKET)}

T.S. Stankevich, Master's student, Immanuel Kant Baltic Federal University e-mail: TSeStankevich@stud.kantiana.ru

The practical features of the design and functioning of the fire automation system of a facility (a market) are considered. Proposals have been formulated to improve the fire automation system of the facility, consisting in replacing the existing system with an analogue addressable fire alarm system and in the development and implementation of an automatic water fire extinguishing system.

Key words: fire, fire automatics, alarm, notification, fire extinguishing 